\title{
LA EFECTIVA CONSTITUCIONALIDAD DE LA REGULACION DE DERECHOS ESTATUTARIOS EN LA STC 31/2010
}

\author{
MIGUEL AGUDO ZAMORA \\ Profesor Titular Derecho Constitucional \\ Universidad de Córdoba
}

\begin{abstract}
SUMARIO
I. Introducción

II. La discusión sobre si los Estatutos de Autonomía son instrumentos jurídicos capaces de regular derechos y deberes

III. ¿Derechos o principios rectores? A propósito de la STC 247/07

IV. La efectiva constitucionalidad de los derechos estatutarios. A propósito de la STC 31/2010

V. Reflexión final
\end{abstract}

\section{INTRODUCCIÓN}

La ola de reformas estatutarias que han tenido lugar en los últimos cinco años en nuestro ordenamiento jurídico ha dado lugar a discusiones jurídico-doctrinales realmente apasionantes. Más allá del uso político-partidista que, por un lado y por el otro, se ha pretendido dar a estas reformas, desde el punto de vista jurídico varios han sido los temas objeto de una interesante, profunda y valiente discusión. Junto a cuestiones identitarias o a la capacidad de los Estatutos de pormenorizar y blindar competencias autonómicas o la efectiva constitucionalidad del principio de bilateralidad, la posibilidad de que los Estatutos de Autonomía regulen derechos ha sido, sin duda, otro de los temas que ha resultado especialmente polémico y, dado el objeto del que se trata, se puede considerar que su tratamiento en la STC 31/2010 constituye uno de los aspectos más relevantes de la misma.

Por el propio ámbito competencial autonómico la mayor parte de los llamados derechos estatutarios se pueden encuadrar dentro de los denominados derechos sociales. De 
esta forma, puede señalarse que uno de los rasgos principales que definen los nuevos Estatutos, que podríamos denominar Estatutos del Siglo XXI, es su marcado carácter social, que coloca a la ciudadanía en el centro de la acción política. Este protagonismo es el resultado de la evolución en el campo social, cultural y económico de los Estados democráticos occidentales en los últimos cincuenta años. Evolución que ha ido acompañada de la consecución de un importante número de logros por parte de las sociedades, muchos de los cuales, al encontrarse recogidos en los ordenamientos jurídicos, hacen realidad el contenido axiológico dimanante de la configuración constitucional del Estado Social.

La llamada crisis del Estado del Bienestar, motivada por los problemas de mantenimiento económico de los mecanismos de protección social, ha evidenciado la necesidad de sustraer determinadas cuestiones del contingente juego político y de las inevitables coyunturas económicas e integrarlas, a través de expresas inclusiones textuales, en las normas jurídico-políticas estructuradoras (Constitución en primer lugar, estatutos regionales, en segundo lugar) de los sistemas políticos. De este modo se las pretende dotar de una mayor garantía y se asegura el compromiso firme de los poderes públicos en el mantenimiento y mejora de estas conquistas sociales.

Por ello, resulta conveniente que las normas políticas fundamentales recojan la doctrina social de los textos internacionales y, de esa forma, establezcan listados de derechos sociales y adecuados sistemas que garanticen una protección social eficaz.

\section{LA DISCUSIÓN SOBRE SI LOS ESTATUTOS DE AUTONOMÍA SON INSTRUMENTOS JURÍDICOS CAPACES DE REGULAR DERECHOS Y DEBERES}

Conviene, en primer lugar, recordar unas ideas ${ }^{1}$ que no por formar parte del más elemental acervo común del Constitucionalismo han de ser silenciadas: el respeto de los derechos constituye el fundamento del orden político y de la paz social en los Estados de Derecho, estableciéndose un estrecho nexo de interdependencia genético y funcional entre el Estado de Derecho y los derechos, ya que el Estado de Derecho exige e implica para serlo garantizar los derechos, mientras que éstos exigen e implican para su realización al Estado de Derecho. La mayor o menor amplitud del reconocimiento constitucional de los derechos, así como el nivel de protección o garantías de los que disfruten, serán un parámetro suficientemente indicativo de la legitimidad democrática del orden político, existiendo una profunda relación entre el papel asignado a los derechos y libertades y el sistema de organización y ejercicio de las funciones estatales. En la normativa constitucional de los países democráticos, los derechos fundamentales gozan, pues, de un doble carácter, presentándose como un conjunto de valores objetivos básicos y como el marco de protección de las situaciones jurídicas subjetivas. Actualmente, desempeñan, por tanto,

1 Sobre este asunto ya hemos tenido oportunidad de pronunciarnos en AGUdo Zamora, M., «Derechos sociales, deberes y políticas públicas», en Comentarios al Estatuto de Autonomía para Andalucía (coord. MUÑOZ Machado, S., Rebollo Puig, M.), Thomson-Aranzadi, Pamplona, 2008. pág. 263 y sgs. Parte del contenido de aquellas reflexiones se reproducen en este epígrafe. 
una doble función: en el plano subjetivo, actúan como garantías de la libertad individual y de los aspectos sociales y colectivos de la subjetividad, mientras que en el objetivo, asumen un componente institucional, funcionando como medio para el logro de los fines y valores constitucionales.

Partiendo del rango de fundamento del orden político que ostentan los derechos, el Tribunal Constitucional ha formulado la doctrina de la doble naturaleza, subjetiva y objetiva, de los derechos fundamentales. Así en la Sentencia 25/81, de 14 de julio, el Tribunal ha declarado que «en primer lugar, los derechos fundamentales son derechos subjetivos, derechos de los individuos no sólo en cuantos derechos de los ciudadanos en sentido estricto, sino en cuanto garantizan un «status» jurídico o la libertad en un ámbito de existencia. Pero al propio tiempo, son elementos esenciales de un ordenamiento objetivo de la comunidad nacional, en cuanto ésta se configura como marco de una convivencia humana justa y pacífica, plasmada históricamente en el Estado de Derecho y, más tarde en el Estado social de Derecho o el Estado social y democrático de Derecho, según la fórmula de nuestra Constitución.»

El primer artículo de nuestra Constitución, tras definir la forma de Estado, proclama como valores superiores del ordenamiento la libertad, la justicia, la igualdad y el pluralismo político. Este precepto se conecta estrechamente con el que inaugura el Título I, que, entre los fundamentos del orden político y de la paz social, incluye la dignidad de la persona humana; pues es evidente que dichos valores superiores del ordenamiento necesitan como presupuesto básico para su plena existencia el íntegro desarrollo ético de los miembros de la sociedad que por ellos se rige. Por lo tanto el reconocimiento de derechos no es sino la manifestada obligación de la primacía del valor constitucional último: la dignidad de la persona humana, al que está íntimamente unido el libre desarrollo de la personalidad ${ }^{2}$. De esta forma se rompe con la antigua concepción estrictamente subjetivista de los derechos fundamentales, pasando éstos a considerarse como elementos del ordenamiento jurídico, esto es, normas jurídicas objetivas que son cúspide del sistema axiológico que informa todos los sectores del Derecho.

Podría entenderse, pues, prima facie, que si se aplicara una lectura reduccionista de la Constitución resultaría escaso el margen del que dispondrían las Comunidades Autónomas, y, por ende, los Estatutos de Autonomía, para incluir cláusulas reguladoras de los derechos y deberes en sus ordenamientos jurídicos debido a la vinculación constitucional de éstos.

En este sentido, Diez Picazo 3 considera que hay argumentos formales y sustantivos serios para sostener que la inclusión de declaraciones de derechos en los Estatutos de Autonomía no es conforme con la Constitución española. Esta teoría fue objeto de réplica por Caamaño ${ }^{4}$, quien considera que el contenido de los Estatutos de Autonomía que la Constitución establece como necesario en su artículo 147.2 no tiene un carácter exclusivo y ex-

2 En esta línea, Peces Barba cree que «la dignidad de la persona es el fundamento y la razón de la necesidad de estos valores superiores, es la raíz última de todo» y que éstos son «los caminos para hacer real y efectiva la dignidad humana». Peces Barba, G., Los valores superiores, Tecnos, Madrid, 1984, págs. 85 a 86.

3 Diez-Picazo, L.M., en «¿Pueden los Estatutos de Autonomía declarar derechos, deberes y principios?», en $R E D C, \mathrm{n}^{\circ} 78,2006$, págs.63 a 75 .

4 CaAmaño, F., en «Sí, pueden (Declaraciones de derechos y Estatutos de Autonomía)», en REDC, n 79, enero-abril 2007, págs.33-46. 
cluyente, por lo que es posible la inclusión de otras materias en los textos estatutarios tales como un listado de derechos y deberes; lo que, además, en opinión de este autor, resulta lógico pues «en un sistema de distribución multinivel del poder político es inevitable la simultaneidad de legisladores de los derechos fundamentales».

El principio de autonomía de las nacionalidades y regiones que conforman el Estado español, convertida en realidad ex constitutione, y el desarrollo evolutivo que han impulsado los entes territoriales, en aras de alcanzar un mayor protagonismo en la vida política, ha dado como resultado una pluralidad de ordenamientos jurídicos diferenciados que conviven armónicamente al estar vinculados por un orden común, el que emana de la aplicación y eficacia del ordenamiento constitucional.

De ello se infiere, como consecuencia estructural del principio de autonomía reconocido en nuestra Constitución, que en el Estado español no puede existir una uniformidad de derechos y obligaciones para todos sus ciudadanos, en la medida que, a pesar de estar vinculados por un ordenamiento común en cuyo vértice se encuentra la Constitución, también están sometidos a ordenamientos jurídicos diferenciados

Aguado sostiene, en opinión contraria, que el reconocimiento de un catálogo de derechos en un Estatuto es difícilmente compatible con nuestra Constitución ${ }^{5}$. Lectura que no comparten los diferentes Consejos Consultivos autonómicos que se han pronunciado sobre esta materia, inclinándose a favor de la inclusión de un catálogo de derechos y deberes en los nuevos textos estatutarios ${ }^{6}$.

Por lo tanto, tal como señala Porras Nadales ${ }^{7}$, «la visión rigurosa de las cosas parece que debe predicarse en rigor de los «auténticos» derechos fundamentales, es decir, de los que se integran en principio dentro de la Sección Primera del Capítulo II del Título I de la Constitución española de 1978: pero al mismo tiempo la existencia de un Estado autonómico implica la subsistencia de una pluralidad de ordenamientos que sería incompatible con la absoluta uniformidad en materia de derechos y deberes de los ciudadanos españoles, como ha reconocido nuestro Tribunal Constitucional». Por lo tanto, si el núcleo fundamental de tales derechos sería pues resistente a cualquier impacto de desigualdad derivado del proceso de descentralización territorial, en cambio el paquete de derechos sociales y principios rectores de la política social y económica, que se ajustan normalmente al perfil competencial propio de las Comunidades Autónomas, podría eludir las posibilidades de una regulación estatal exhaustiva y completa permitiendo a las Comunidades Autónomas priorizar o de no determinados valores propios del Estado de bienestar.

Es cierto que la Constitución española no contiene ninguna previsión mediante la cual apodere de manera expresa a las Comunidades Autónomas para crear un catálogo propio de derechos y deberes. Es más, los anteriores Estatutos de Autonomía solían in-

5 Aguado Renedo, C., en El Estatuto de Autonomía y su posición en el ordenamiento jurídico (1996).

6 Dictamen 268/05 del Consejo Consultivo de la Generalitat de Cataluña; Dictamen 782/05 del Consejo Consultivo de Galicia; Dictamen 72/06 del Consejo Consultivo de Andalucía; Dictamen 68/06 del Consejo Consultivo del Principado de Asturias y Dictamen 713/06 del Consejo Consultivo de Castilla y León. Todos estos textos se encuentran también publicados en «Dictámenes sobre las reformas estatutarias», en Revista Española de la Función Consultiva, $n^{\circ}$ extraordinario de 2007.

7 Porras Nadales, A., en «Derechos sociales y políticas públicas», en El Estatuto de Autonomía de Andalucía de 2007 (Coord. Agudo Zamora, M.), Centro de Estudios Andaluces, 2007, pág. 62 y sgs. 
cluir cláusulas de remisión en las que se indicaba que los derechos y deberes de los ciudadanos de la Comunidad Autónoma eran los establecidos en la Constitución.

Ahora bien, una cuestión es que todos los españoles sean titulares de los derechos y deberes reconocidos en la Constitución y otra bien distinta es que las Comunidades Autónomas no puedan desarrollar aspectos relativos al contenido o condiciones de ejercicio de los derechos y deberes o reconocer nuevos derechos y deberes, más allá de los constitucionalmente reconocidos.

Por lo tanto, cabe preguntarse: ¿existen límites constitucionales para incluir una tabla de derechos en un Estatuto de Autonomía? A esta pregunta se debería responder aportando tres datos sustanciales: primero, la Constitución no lo impide; segundo, los contenidos que señala el artículo 147.2 de la Constitución como contenido necesario de los Estatutos de Autonomía son los mínimos, por lo que éstos pueden regular otras materias; y, tercero, es recomendable que se incluya la mencionada tabla como expresión del pluralismo político que, como valor superior del ordenamiento jurídico, afianza y preserva el principio democrático, vertebrador de nuestro Estado.

Ahora bien, ¿qué derechos son los que se podrían incluir en los Estatutos?

Los derechos fundamentales y las libertades públicas no se pueden regular. En virtud del juego combinado de los artículos 53 y 81 de la Constitución esta materia queda reservada al legislador orgánico, por lo tanto estatal. Por ello, el contenido esencial de estos derechos y libertades no es necesario repetirlo ni posible modificarlo en los Estatutos de Autonomía. Esto no impide que se puedan regular por las Comunidades Autónomas aspectos no básicos siempre que éstas sean competentes en el ámbito en que se proyecta el derecho en cuestión.

Los derechos contenidos en la Sección Segunda del Capítulo Segundo del Título Primero y los contenidos en el Capítulo Tercero de este Título gozan de reserva de ley estatal o autonómica según el correspondiente título competencial. Quizá fuera conveniente, respecto a los derechos de contenido social, atribuir más facultades a las Comunidades Autónomas, con lo que se institucionalizaría un espacio competencial más estable y eficaz ${ }^{8}$.

Antes de seguir avanzando, debemos, sucintamente, recordar dos cláusulas constitucionales que pueden afectar al ejercicio de competencias autonómicas en este ámbito. Se trata de las previsiones contenidas en los artículos 139.1 y $149.1 .1^{\circ}$ de la Constitución.

El texto literal del artículo 139.1 («Todos los españoles tienen los mismos derechos y obligaciones en cualquier parte del territorio del Estado») no impide regulaciones diferentes por las Comunidades Autónomas sino trato discriminatorio a los españoles.

8 M. BARCeló, en la ponencia presentada ante el Consejo Asesor, creado en Andalucía, para la Modernización del Estado de las Autonomías titulada «El reconocimiento y regulación de los derechos y deberes de los ciudadanos en el Estatuto de Autonomía de Andalucía», señala que a la hora de la división competencial entre el Estado y las Comunidades Autónomas hay que tener en cuenta lo siguiente: a) si el constituyente ha pretendido una regulación homogénea, ha dotado al Estado central de una competencia exclusiva: básicamente para la mayoría de los derechos de la sección primera, capítulo segundo del Título I, que viene reforzada, además, por una reserva de ley orgánica; b) si, por el contrario, ha considerado que sólo era necesario exigir un mínimo de homogeneidad, ha atribuido al Estado central una competencia para dictar la normativa básica; c) y si, por el contrario, ha decidido que la mejor solución se encuentra, para un grupo de determinados derechos o mandatos a los poderes públicos, en una regulación en la que predomine la heterogeneidad, ha posibilitado que sea asumida por las Comunidades Autónomas en toda su plenitud y extensión. 
Por su parte, que el Estado tenga competencia exclusiva sobre la regulación de las condiciones básicas que garanticen la igualdad de todos los españoles en el ejercicio de los derechos y en el cumplimiento de los deberes constitucionales $\left(149.1 .1^{\circ} \mathrm{CE}\right)$ impide que la Comunidades Autónomas puedan regular sobre el contenido esencial de esos derechos, pero no excluye la posibilidad de regular determinados aspectos de los mismos en virtud de los títulos competenciales atribuidos.

Por lo tanto, podemos señalar que las Comunidades Autónomas tienen reconocida capacidad de actuación en materia de derechos y deberes en tres ámbitos distintos:

- para regular, en la medida que sean competentes (regulación del contenido de los derechos o de las condiciones de ejercicio), los derechos y deberes contenidos en la Constitución;

- para transformar en derechos subjetivos los llamados «principios rectores» del Capítulo Tercero del Título I;

- para reconocer nuevos derechos no contemplados en la Constitución, cuyo establecimiento pueda derivarse de un determinado título competencial autonómico.

Por lo tanto, en la medida en que los Estatutos registren nuevos derechos y amplíen los ya existentes, acometerán la consecución del fin último de los Estados, llamados de Bienestar: propugnar la calidad de vida de los ciudadanos, y en última instancia, su felicidad ${ }^{9}$. Más concretamente, la Constitución española propugna una serie de valores superiores de su ordenamiento, cuales son la libertad, la justicia, la igualdad y el pluralismo político, que comprometen a la Comunidad Autónoma como poder público, máxime cuando la Constitución le ha encomendado el encargo de "promover (en el ámbito de sus competencias) las condiciones para que la libertad y la igualdad del individuo y de los grupos en que se integra sean reales y efectivas; remover los obstáculos que impidan o dificulten su plenitud...» (art. 9.2 CE), valores estos que necesariamente alumbran el catálogo estatutario de derechos y deberes. Por lo tanto, en primer lugar, la regulación de este catálogo es materia reservada al Estatuto, en la medida que expresa el entramado de relaciones jurídicas y de poder entre la Comunidad Autónoma y sus propios ciudadanos, derivado éste de las competencias asumidas por aquélla. Y, en segundo lugar, porque la institución en el Estatuto de este marco fundamental de relaciones jurídicas entre los ciudadanos y los poderes públicos vincula de forma directa a éstos últimos en el momento de ejercer sus facultades normativas y de actuación.

9 Sobre la evolución del Estado social en clave autonómica y regional, entre otros, puede verse: AJA, E., El Estado autonómico. Federalismo y hechos diferenciales, 2a ed., Alianza, Madrid, 2003; Cámara, G., CANO, J (eds.), Estudios sobre el Estado Social. El Estado social y la Comunidad Autónoma de Andalucía, Madrid, Tecnos, Parlamento de Andalucía, 1993; VIDAL. J. M., García Herrera, M.A. (eds.), El Estado autonómico: integración, solidaridad, diversidad, Colex/INAP, Madrid, 2005; SCHARPF, F., «Unione europea e welfare state nazionali», Rivista Italiana di Scienza Politica, n. ${ }^{\circ}$ 1, 1996; Porras, A. «Estado social y Estado Autonómico», en Estudios de Derecho Público. Homenaje a Juan José Ruiz-Rico, Tecnos, Madrid, vol. II, 1997; SÁEnz RoYo, E., Estado social y descentralización política. Una perspectiva constitucional comparada de Estados Unidos, Alemania y España, Civitas, Madrid, 2003. 


\section{III. ¿DERECHOS O PRINCIPIOS RECTORES? A PROPÓSITO DE LA STC $247 / 07$}

Debido a su importante presencia en los nuevos Estatutos de Autonomía ha vuelto a tomar importancia el clásico tema del valor y eficacia de los principios rectores de la política social y económica. Como hemos tenido oportunidad de apreciar ${ }^{10}$, la particular naturaleza de estos principios ha llevado al Tribunal Constitucional ${ }^{11}$ a señalar que su carácter vinculante pasa:

$1^{\circ}$ por reconocer que tales principios no son normas jurídicas sin contenido y que enuncian auténticas proposiciones vinculantes que, en cualquier caso, deben de informar la legislación positiva y la práctica judicial, de manera que obligan a los poderes públicos - legislativo, ejecutivo y, en particular, al judicial por la función de aplicación del Derecho que desarrolla - a tenerlos presentes en la interpretación tanto de las restantes normas constitucionales como de las leyes.

$2^{\circ}$ por afirmar que estos principios, en los términos que están protegidos en el artículo 53.3 CE, tienen limitada su efectividad, siendo principios que deben de orientar la actuación de los poderes públicos pero que no generan por sí mismos derechos judicialmente actuables, de suerte que en ocasiones habrá que esperar a que el legislador realice la regulación correspondiente, si bien eso no quita para que los mismos, como contenidos constitucionales mínimos que son, puedan invocarse directamente ante los tribunales sin que aquélla se haya producido.

La doctrina que ha sentado el Tribunal Constitucional bien podría valer cuando nos estamos refiriendo a los principios rectores de las políticas públicas que, en un número que supera ampliamente la centena ${ }^{12}$, se recogen en los últimos Estatutos. En suma, tal como señala López Menudo ${ }^{13}$, «un tema viejo vertido en odres nuevos». Para este autor, estos principios rectores no tienen la fuerza que es propia de los clásicos derechos constitucionales civiles y políticos, mas ello no permite subestimar su valor jurídico, debiendo por el contrario afirmarse que «se trata de genuinas normas jurídicas — «mandatos de optimización»—-cuya configuración jurídica define el artículo 53.3 del texto constitucional. Todo lo anterior se desprende de la Constitución de modo claro así como que tales principios van dirigidos a todos los poderes públicos y, por ende, a los legisladores autonómicos. De lo expuesto va de suyo que son deberes y no simples facultades, lo cual significa que la Constitución compele a seguir la dirección marcada, a realizar la obra bosquejada por el Cap. III, Tít. I CE en conjugación con el artículo 53.3 y el fondo principial resultante de los artículos $1.1^{\circ}$ y $9.2 \mathrm{CE} »^{14}$.

10 Agudo Zamora, M., «El Poder Judicial como garante de la consecución del Estado Social», El Poder Judicial (coord. Miguel Revenga SánCHEZ), ed. Tirant Lo Blanch, Valencia, 2009. págs. 555 y sgs.

11 Entre otras, la STC 14/92, de 10 de febrero.

12 Ver cuadro incluido en Agudo Zamora, M., «Necesidad y eficacia de los principios rectores de las políticas públicas en los nuevos Estatutos de Autonomía», Treinta años de Constitución, ed. Tirant Lo Blanch, Valencia, 2010. págs. 375 y sgs. De este trabajo se han extraído algunas reflexiones respecto al alcance de los principios rectores de las políticas públicas en los Estatutos de Autonomía que aquí se exponen.

13 López Menudo, F. «Los derechos sociales en los Estatutos de Autonomía». Ponencia presentada al IV Congreso de la Asociación Española de Profesores de Derecho Administrativo (AEPDA), pendiente de publicación.

14 Continúa señalando el autor, que «cualquier legislador podría convertir en genuinos derechos subje- 
La STC $247 / 07$, en su FJ $13^{\circ}$, hace una referencia general a a los principios rectores de la política social y económica establecidos en el capítulo III del título I de la propia Constitución que, mutatis mutandi, sirve para ilustrar la efectividad de los principios rectores incluidos en los nuevos Estatutos: «estos principios rectores se caracterizan porque, aunque informan «la legislación positiva, la práctica judicial y la actuación de los poderes públicos», tienen, de acuerdo con su propio enunciado constitucional, una naturaleza muy diversa y, en todo caso, «sólo podrán ser alegados ante la Jurisdicción ordinaria de acuerdo con lo que dispongan las leyes que los desarrollen» (art. 53.3 CE). Estos principios carecen, por tanto, de las notas de aplicabilidad y justiciabilidad inmediatas que caracterizan a los derechos constitucionales, aunque tienen, sin duda, el valor constitucional expresado respecto de todos los poderes públicos, también en este caso sin distinción, orientando sus respectivas actuaciones»; por lo tanto, informando la legislación positiva, la práctica judicial y la actuación de los poderes públicos.

Por esto, hay que tener en cuenta la importancia del contenido del principio rector en relación a la implementación de medidas sociales elementales, a evitar políticas contrarias a dichos principios rectores o a luchar contra la paralización del proceso de mejora de las acciones y servicios y, desde luego, para batallar decididamente contra una eventual regresión de los niveles de atención social ya logrados.

Siguiendo con el paralelismo, cabe plantearse ${ }^{15}$ si los principios rectores que están enunciados en un Estatuto se encuentran, respecto de su Comunidad Autónoma concreta, en análoga posición a la que ocupan los principios rectores de la política social y económica respecto de todos los poderes públicos del Estado. Pues bien la respuesta exige distinguir entre los principios insertos en el Estatuto que sean pura reproducción de los constitucionales de dicho Capítulo III y los principios de nuevo cuño surgidos del poder dispositivo del estatuyente autonómico.

En relación con los primeros, al tratarse de principios rectores constitucionales simplemente reproducidos, podría decirse que su fuerza de obligar deriva de la Constitución misma y no del Estatuto, con la salvedad de que el mandato que se encuentra en el principio rector constitucional se rigidiza al plasmarse en el Estatuto pues así el legislador autonómico queda más intensamente vinculado, o dicho con otros términos, el principio se «congela». Efecto de rigidez que aún será mayor si los principios rectores constitucionales son calificados como derechos subjetivos por el Estatuto, que así añadiría a tales principios rectores una carga de gravedad jurídica pretendida por la propia Constitución (art.53.3 CE), aunque matizada por la doctrina del Tribunal Constitucional en la nombrada STC $247 / 07$.

tivos todos y cada uno de los «derechos sociales» que se citan en ese Cap. III — en la medida en que ello sea técnicamente posible - con lo cual habría logrado ejecutar óptimamente ese desiderátum constitucional. Ahora bien, la Constitución no exige que se llegue necesariamente a esa meta, que ni siquiera menciona en relación con algunas de las materias contenidas en dicho Capítulo (formación profesional, promoción de la ciencia y la investigación, participación de la juventud, protección de consumidores y usuarios, etc.). Dicho de otra forma, aunque potencialmente todos los principios rectores pueden llegar a convertirse en derechos públicos subjetivos ello no es necesario para dar cumplimiento al postulado del Estado social ínsito en la Constitución. En el desarrollo de ese postulado existen otros hitos o grados, otras acciones capaces de sintonizar con la dirección querida por el texto constitucional», op. cit., pág. 72 .

15 Ver López Menudo, op. cit., pág. 74. 
Pero, precisamente, esta sentencia al señalar que los derechos que enuncian los nuevos Estatutos no son verdaderos derechos ${ }^{16}$, sino que se ha producido una «degradación universal de los derechos públicos subjetivos a la condición de principios rectores o de mandatos» ${ }^{17}$, coloca en el mismo nivel jurídico a los principios rectores, que pasan, pues, a tener un mayor protagonismo en el conjunto de las normas estatutarias.

Muñoz Machado, por su parte, señala que las normas programáticas estatutarias no tienen el mismo valor que las normas programáticas de la Constitución, y que no son vinculantes, porque «la congelación de opciones políticas y organizativas sólo se produce en el texto constitucional, pero no es función propia del legislador ordinario que, en definitiva, es quien aprueba el Estatuto», concluyendo que «no tiene cobertura constitucional esta pretensión de vincular al legislador regional futuro» ${ }^{18}$. Opinión que considero superada por la doctrina ya expuesta del Tribunal Constitucional en su sentencia $247 / 07$.

Por tanto, los principios rectores estatutarios vinculan al legislador autonómico. La STC 247/2007 ha venido a respaldar la idea de que los principios rectores estatutarios se encuentran frente a la Comunidad Autónoma respectiva en similar posición que los principios rectores constitucionales frente a todos los poderes públicos. Así, pues, se trasplantan al plano autonómico las mismas cuestiones que históricamente han planteado las relaciones entre las normas programáticas — configuradas como principios rectores por la Constitución-y la actividad pública para el desarrollo de éstos, a saber qué ocurre si el legislador ordinario dicta leyes que no concuerdan con el sentido de algún principio rector; si no impulsa lo mandado por los principios rectores; y si se dictan medidas regresivas respecto de los niveles de bienestar ya alcanzados.

En cuanto al alcance regulador del régimen de los principios, si no se desarrollan normativamente regirán las reglas que la Constitución y el propio tenor literal de los Estatutos refiere a los principios rectores: informan la legislación positiva, la práctica judicial y la actuación de los poderes públicos; pero si la ejecución del principio rector deviene en una plasmación efectiva como derecho subjetivo, su régimen será el que es propio de los mismos (accionabilidad ante los Tribunales) ${ }^{19}$.

16 «Nada impide que el Estatuto de Autonomía en cuanto norma institucional básica de la Comunidad Autónoma, al atribuir las competencias que han de ejercer los poderes públicos autonómicos, les impongan, de modo directo, criterios o directrices para su ejercicio o que lo hagan, de modo indirecto, mediante la formalización de enunciados o declaraciones de derechos a favor de los particulares. Se trata, en ambos casos, de mandatos al legislador y restantes poderes públicos autonómicos, imponiéndoles prescripciones que son vinculantes para los mismos con independencia de la veste de que se revistan» (FJ. 14).

17 Op. cit., pág. 75.

18 Muñoz Machado, S., Derecho Público de las Comunidades Autónomas, 2a ed., Iustel, Madrid, 2007, pág. 382.

19 Por tanto, tal como señala López Menudo, op. cit., pág. 73, «es posible hablar de un itinerario cuyo punto de partida radica en la nuda letra del Cap. III, Tít. I de la Constitución y su término en el hecho mismo de la creación de derechos subjetivos. En los puntos intermedios de ese trayecto hay un universo de acciones posibles: despliegue de medios personales, de recursos económicos y materiales, adopción de medidas jurídicas, imposición de deberes a terceros, creación de organizaciones, establecimiento de instalaciones, centros, etc. Los poderes públicos vienen obligados a insertarse en ese itinerario, aunque la Constitución no fije, por lo que se refiere al legislador, el dónde de esa incorporación ni el cuándo. Ciertamente, la Constitución no predetermina qué han de hacer los poderes públicos ni cuánto han de hacer para que pueda considerarse que cumplen esos principios, lo que obliga a reconocer que el legislador cuenta con un amplio margen de discrecionalidad — salvo que 
En todo caso, en los propios Estatutos se compele a los poderes públicos autonómicos a que adopten las medidas necesarias para el efectivo cumplimiento de estos principios ${ }^{20}$ mediante el impulso de la legislación pertinente, la garantía de una financiación suficiente y la eficacia y eficiencia de las actuaciones administrativas ${ }^{21}$.

\section{LA EFECTIVA CONSTITUCIONALIDAD DE LOS DERECHOS ESTATUTARIOS. A PROPÓSITO DE LA STC 31/2010}

\section{IV.1 AlCANCE DE la CONSTitucionalidad de la INCLUSión DE DERECHOS ESTATUTARIOS}

La STC 31/2010 no es la primera en la que el Tribunal Constitucional se pronuncia sobre la legitimidad constitucional de una declaración de derechos y principios rectores incluida en los Estatutos de Autonomía. La STC 247/2007, que resolvió el recurso planteado contra la reforma del Estatuto de Autonomía de Valencia, estableció que el contenido del Estatuto puede ir más allá del establecido, como de necesario cumplimiento, por el artículo 147.2 CE, por lo que no existe impedimento alguno para que el Estatuto, como norma institucional básica de la Comunidad Autónoma, incluya derechos en su texto. Ahora bien, tal como recuerda Carrillo ${ }^{22}$, «después de introducir una singular distinción entre «derechos institucionales» $\mathrm{y}$ «derechos competenciales», el Tribunal precisó que, fuera cuál fuera la denominación utilizada por los Estatutos, los llamados derechos estatutarios no son en realidad derechos subjetivos sino simples mandatos a los poderes públicos autonómicos. Ahora, con motivo de la STC 31/2010 (FJ 16º), mantiene que los derechos estatutarios —a los cuales se refiere con esta denominación- no son derechos subjetivos sino mandatos a los poderes públicos, pero parece abandonar la controvertida distinción — porque no hace ninguna referencia— entre los que quedan vinculados a los funcionamientos de las instituciones y los que lo están al ejercicio específico de competencias».

Así, señala que «ya en la propia Constitución bajo el término «derecho» se comprenden tanto verdaderos derechos subjetivos como cláusulas de legitimación para el desarrollo de determinadas opciones legislativas, si bien en ambos casos se trata siempre, al cabo, de mandatos dirigidos al legislador, bien imponiéndole un hacer o una omisión que

se trate de mandatos constitucionales concretos - para andar ese camino en función de las circunstancias políticas y económicas reinantes. Pero no es discrecional la decisión misma de seguir o no dicho diseño, y en esto se advierte la existencia de un cierto «contenido esencial» en los principios rectores, si bien se trate de un «núcleo» mucho más pequeño y menos «duro» que el de los derechos fundamentales propiamente dichos. Todo esto que acaba de apuntarse plantea problemas dificultosos y exige ser tratado meticulosamente. Pero de entrada debe quedar en primer plano la idea de que aunque el legislador está vinculado por los principios rectores goza de una discrecionalidad notable (aunque no absoluta) y por ello los jueces y tribunales han de actuar con especial prudencia para no incurrir en un «activismo judicial» improcedente en este ámbito».

20 Estatuto de Autonomía de Cataluña (art. 39.1) y Estatuto de Autonomía de Castilla-León (art. 16).

21 Estatuto de Autonomía de Andalucía (art. 40.2).

22 Carrillo, M., «Derechos y garantías jurisdiccionales», en Revista Catalana de Derecho Público. Número especial sobre la STC 31/2010, agosto 2010. 
se erigen en objeto de una pretensión subjetiva exigible ante los Tribunales de justicia; bien obligándole a la persecución de un resultado sin prescribirle específicamente los medios para alcanzarlo y sin hacer de esa obligación el contenido de ningún derecho subjetivo, que sólo nacerá, en su caso, de las normas dictadas para cumplir con ella. Normas, en definitiva, que prescriben fines sin imponer medios o, más precisamente, que proveen a la legitimación de la ordenación política de los medios públicos al servicio de un fin determinado».

El Tribunal entiende, pues, que estos derechos estatutarios no son derechos subjetivos sino mandatos al legislador, para diferenciarlos de los derechos fundamentales reconocidos por la Constitución, y que, por lo tanto, los derechos estatutarios sólo vinculan al legislador autonómico 23 . Esto supone, según el Tribunal Constitucional, que sólo serán exigibles ante los órganos judiciales cuando el legislador autonómico los haya desarrollado mediante ley. Igualmente, los derechos estatutarios son derechos materialmente vinculados al ámbito competencial propio de la comunidad autónoma; es decir, son las competencias reconocidas en el Estatuto las que delimitan el ámbito en que los derechos estatutarios pueden operar.

En efecto, el Tribunal en el FJ $16^{\circ}$ de la STC 31/2010 recuerda que «derechos fundamentales son, estrictamente, aquellos que, en garantía de la libertad y de la igualdad, vinculan a todos los legisladores, esto es, a las Cortes Generales y a las Asambleas legislativas de las Comunidades Autónomas, sin excepción. Esa función limitativa sólo puede realizarse desde la norma común y superior a todos los legisladores, es decir, desde la Constitución, norma suprema que hace de los derechos que en ella se reconocen un límite insuperable para todos los poderes constituidos y dotado de un contenido que se les opone por igual y con el mismo alcance sustantivo en virtud de la unidad de las jurisdicciones (ordinaria y constitucional) competentes para su definición y garantía. Derechos, por tanto, que no se reconocen en la Constitución por ser fundamentales, sino que son tales, justamente, por venir proclamados en la norma que es expresión de la voluntad constituyente». Por esto, los derechos estatutarios «han de ser, por tanto, cosa distinta».

Como ya hemos señalado en el segundo apartado de este trabajo se trataría, pues, de derechos que sólo vinculan al legislador autonómico y, además, materialmente vinculados al ámbito competencial propio de la Comunidad Autónoma. Ahora bien, señala la STC 31/2010, «bajo la misma categoría «derecho» pueden comprenderse realidades nor-

23 Hay que recordar, en este punto, que los magistrados Conde Martín de Hijas, Delgado Barrio y Rodríguez Arribas en sus respectivos Votos Particulares a la STC 31/2010 entienden este asunto de forma discrepante. Así Conde Martín de Hijas sostiene que los derechos estatutarios no son sólo mandatos a los poderes públicos sino que lo son efectivamente dado que se regula incluso un régimen de garantías de los mismos, que llega hasta una vertiente jurisdiccional. Al entender este magistrado que no cabe en el texto estatutario la inclusión de derechos sostiene la inconstitucionalidad de los artículos impugnados relativos a derechos. Delgado Barrio propugna que dado que los Estatutos de Autonomía son cauce de diferenciación entre las Comunidades Autónomas no son, pues, el ámbito normativo adecuado para el establecimiento de derechos que han de implicar diferencias, por lo que su inclusión en el Estatuto ha de estar inspirada por un criterio profundamente restrictivo. Concluye, por lo tanto, que, salvo excepciones, la regla general ha de ser la no viabilidad de la inclusión de derechos en los Estatutos. Por su parte, Rodríguez Arribas se centra fundamentalmente en la necesidad de haber realizado una declaración interpretativa acerca del efecto de la constitucionalidad de los artículos 20 y 21.2 EAC, a los que nos referiremos en el siguiente epígrafe. 
mativas muy distintas, y será a éstas a las que haya de atenderse, más allá del puro nomen, para concluir si su inclusión en un Estatuto es o no constitucionalmente posible».

Este tipo de derechos estatutarios, tal como hemos señalado al tratar en el apartado anterior la STC 247/2007, no son derechos subjetivos sino mandatos a los poderes públicos, por lo que operan técnicamente como pautas, prescriptivas o directivas, según los casos, para el ejercicio de las competencias autonómicas. Esto supone, por lo tanto, y tal como señalamos en el segundo apartado de este trabajo, un principio de diferenciación que no puede confundirse con la desigualdad o el privilegio prohibidos por los arts. 138.2 y $139.1 \mathrm{CE}$, pues con ella «sólo se abunda en la diversidad inherente al Estado autonómico» tal como tuvo oportunidad de pronunciarse la STC 76/1983.

Por otra parte, el Tribunal entiende que la función de desarrollo de los derechos fundamentales no corresponde a los Estatutos de Autonomía sino que es misión del legislador autonómico, en tanto que legislador ordinario y de acuerdo cono el reparto constitucional de competencias, pero no del legislador orgánico estatuyente ${ }^{24}$. En este sentido, según el criterio del Tribunal y tal como subraya críticamente Carrillo, no existe ninguna contradicción que aquello que puede hacer el legislador ordinario le sea impedido al legislador estatutario, porque — afirma — «en realidad, no es que pueda hacerse más por ley autonómica; es que se hace cosa distinta, como corresponde en el juego de normas ordenadas con arreglo al criterio de competencia».

Carrillo ${ }^{25}$ entiende que esta interpretación sobre la legitimidad constitucional de la previsión estatutaria de un título sobre derechos, deberes y principios, ofrece algunos

24 «La distribución competencial que opera entre las propias leyes orgánicas explica que el Estatuto de Autonomía no pueda regular toda la materia que en principio se reserva al género de la ley mediante la cual se aprueba, pues en ocasiones la reserva orgánica lo es, de manera exclusiva y excluyente, a una ley orgánica determinada (así, LOPJ), o a una especie del género común. Este último es el caso de las leyes orgánicas de desarrollo de los derechos fundamentales (art. $81 \mathrm{CE}$ ). Esa función de desarrollo no puede acometerse en una ley orgánica de aprobación de un Estatuto de Autonomía; y ello por razones que tienen que ver con la condición del Estatuto como norma institucional básica, por un lado, y con su vigencia territorial limitada, por otro.

Lo primero supone que el Estatuto de Autonomía, como norma primera de un sistema normativo autónomo, tiene su ámbito más propio en el terreno de la generalidad, la abstracción y los principios, lo que no se compadece con la disciplina de desarrollo de un derecho fundamental cuya proclamación y definición sustancial (contenido mínimo) ya se habrá verificado en la Constitución, de suerte que la intervención del Estatuto sólo sería admisible si fuera reiterativa; esto es, si se limitara a hacer lo que ya se ha hecho en la Constitución, en la que se agota la función normativa necesaria en ese primer nivel de abstracción, al que sólo puede seguir ya la función de desarrollo, proceso de concreción que no corresponde al Estatuto. Lo segundo implica que la participación del Estatuto en el desarrollo de los derechos redundaría en una pluralidad de regímenes de derechos fundamentales (tantos como Estatutos), lo que afectaría al principio de igualdad de los españoles en materia de derechos fundamentales.

De otra parte, la divisoria ley orgánica/ley ordinaria en materia de derechos fundamentales (desarrollo/regulación: arts. 81.1 y 53.1 CE) supone que el Estatuto, en tanto que ley orgánica, tampoco puede, no ya declarar o desarrollar derechos fundamentales o afectar a los únicos que son tales, sino siquiera regular el ejercicio de tales derechos. Podrá hacerlo, en su caso, el legislador autonómico, en tanto que legislador ordinario y de acuerdo con el reparto constitucional de competencias, pero no el legislador (orgánico) estatuyente. De ahí que no haya paradoja alguna en el hecho de que por simple ley autonómica (ley ordinaria) pueda hacerse lo que no cabe en un Estatuto (norma superior a la autonómica). En realidad, no es que pueda hacerse más por ley autonómica; es que se hace cosa distinta, como corresponde en el juego de normas ordenadas con arreglo al criterio de competencia.» (FJ 17).

25 Op. cit., pág. 2. 
puntos débiles. En primer lugar, los derechos estatutarios no son siempre diferentes de los derechos fundamentales reconocidos en la Constitución. Y en segundo lugar, no está claro que el legislador estatutario — siempre dentro de su ámbito competencial— no pueda prefigurar el contenido de aquellos derechos que acoge, con mayor o menor precisión.

\section{IV.2 LA CONSTITUCIONALIDAD DE DETERMINADOS DERECHOS INCLUIDOS EN EL Estatuto de Autonomía de Cataluña}

El Tribunal Constitucional en los fundamentos jurídicos $18^{\circ}, 19^{\circ}$ y $20^{\circ}$ de la STC $31 / 2010$ ha tenido ocasión de manifestarse acerca de la constitucionalidad de tres preceptos del Estatuto de Autonomía de Cataluña (arts. 15, 20 y 21.1 y 2) ${ }^{26}$, referentes a los derechos de las personas en general, al derecho a vivir con dignidad el proceso de la muerte y a los derechos y deberes en el ámbito educativo.

\section{a. Derechos de las personas}

En relación al artículo 15 EAC, conviene reseñar que el FJ.18 $8^{\circ}$ STC 31/2010 recuerda que el apartado 1 de este artículo («Los ciudadanos de Cataluña son titulares de los derechos y deberes reconocidos por las normas a que se refiere el artículo $4.1 »$ ) ha de interpretarse en conjunción con el tenor del artículo 37.4, que hace expresa salvedad de los derechos fundamentales reconocidos en la Constitución y en los tratados y convenios internacionales ratificados por España, que no pueden verse afectados por los derechos y principios reconocidos en el EAC. Derechos y principios que, además, tampoco han de suponer «una alteración del régimen de distribución de competencias, ni la creación de títulos competenciales nuevos o la modificación de los ya existentes». Por lo tanto, se desprende «de un lado, que ni el Estatuto ha creado derechos fundamentales distintos de los proclamados en la Constitución o en contradicción con ellos, ni ha podido afectar al régimen de tales derechos en lo que hace a su titularidad, regulación y condiciones de ejercicio. De otro lado, que, en lo que hace a los derechos y principios enunciados en el Estatuto, su proclamación no puede implicar alteración alguna del ámbito de las competencias autonómicas definido a partir del régimen constitucional de distribución de competencias; esto es, que dicha proclamación ha de operar siempre, y sólo, sobre el presupuesto de las concretas competencias atribuidas a la Generalitat de Cataluña de conformidad con las previsiones constitucionales».

En relación al segundo apartado, que proclama el derecho de todos «a vivir con dignidad, seguridad y autonomía, libres de explotación, de malos tratos y de todo tipo de discriminación» así como «al libre desarrollo de su personalidad y capacidad personal», el Tribunal Constitucional (FJ.18 $)$ entiende que una proclamación tan genérica y abstracta como la que reconoce el «derecho a vivir con dignidad, seguridad y autonomía, libres de explotación, de malos tratos y de todo tipo de discriminación» y el «derecho al libre desarrollo de su personalidad y capacidad personal» no hace del art. 15.2 EAC sino

26 Dejamos a un lado, sin tratar en este artículo, los derechos del ámbito lingüístico, pues su estudio merecen un tratamiento específico y mucho más extenso. 
«el mero enunciado redundante de las palabras del art. 10.1 CE y de las proclamaciones internacionales de derechos más principales». Se trata, pues, del enunciado de los valores y principios en los que la Constitución fundamenta el orden político y la paz social. No encuentra, por tanto, el Tribunal Constitucional declaración alguna de derechos subjetivos, sólo la expresión formal de la voluntad de comunión del Estatuto con el fundamento declarado del orden de convivencia ordenado desde la Constitución».

Por su parte, el art. 15.3 EAC dispone que los derechos reconocidos en el Estatuto «pueden extenderse a otras personas, en los términos que establezcan las leyes». Esta referencia al principio de legalidad y a la necesaria correspondencia que ha de mediar entre los derechos y principios estatutarios, de un lado, y el ámbito de las competencias (y de su ejercicio) de la Comunidad Autónoma, por otro, provoca que los derechos reconocidos en el Estatuto sólo pueden vincular a los poderes públicos catalanes y tener por titulares a los ciudadanos de Cataluña. Titularidad que puede extenderse a otros españoles o, en su caso, a los extranjeros, siempre «en los términos que establecen las leyes», que «habrán de ser, en cada caso, las leyes competentes; es decir, también, eventualmente, las leyes del Estado» $\left(\mathrm{FJ} .18^{\circ}\right)$.

\section{b. Derecho a vivir con dignidad el proceso de la muerte}

El art. 20 EAC reconoce el «derecho a recibir un adecuado tratamiento del dolor y cuidados paliativos integrales y a vivir con dignidad el proceso de su muerte», así como el «derecho a expresar su voluntad de forma anticipada para dejar constancia de las instrucciones sobre las intervenciones y los tratamientos médicos que puedan recibir»; instrucciones que, de acuerdo con el precepto, «deben ser respetadas en los términos que establecen las leyes». Un derecho al tratamiento del dolor y a los cuidados paliativos perfectamente compatible con el derecho fundamental a la vida y a la integridad física y moral (art. $15 \mathrm{CE}$ ), del que, señala el Tribunal Constitucional (FJ19 $9^{\circ}$ «es, incluso, una consecuencia obligada, por implícita, de la garantía de ese derecho fundamental, al que, por ello, ni contradice ni menoscaba». Por ello, vivir con dignidad el proceso de la muerte no es sino una manifestación del derecho a la vida digna, «sin que necesariamente se implique con ello el derecho a la muerte asistida o a la eutanasia» (FJ $\left.19^{\circ}\right)$.

Por otra parte, el derecho a dejar constancia de la voluntad para el caso de no poder manifestarla en el momento de recibir tratamiento médico no afecta al derecho a la vida. El Tribunal Constitucional señala que, en cambio, la obligación de respeto a esa voluntad lo será «en los términos que establecen las leyes».

En relación a este asunto, se puede entender que el Tribunal Constitucional, con la intención de poner de relieve que no se trata de un nuevo derecho, se ha esforzado en argumentar que la proclamación de un derecho al tratamiento del dolor y a los cuidados paliativos forma parte del derecho a la vida y a la integridad física y moral. Pero no es irrelevante, señala Carrillo, que no sea un precepto inocuo que el legislador —en este caso el estatutario - haya decidido dar sustantividad propia a los tratamientos que tienen que recibir las personas en la fase terminal de su vida, incorporándolos en el capítulo de los derechos del ámbito civil y social, del Estatuto, pues supone un mandato explícito al legislador que predetermina el ejercicio de derechos subjetivos de libertad y las consiguientes obligaciones sobre el personal sanitario, que el legislador competente tendrá que 
concretar. Y «es en este ámbito de la gestión sanitaria, en el cual están presentes derechos fundamentales de las personas, donde el legislador estatal tendrá que situarse, para incorporar en su legislación sobre la materia los deberes que corresponden al personal sanitario, con el fin de garantizar el cumplimiento de las últimas voluntades del paciente» ${ }^{27}$.

\section{c) Derechos y deberes en el ámbito de la educación}

El art. 21.1 EAC proclama el derecho de todos a «una educación de calidad y a acceder a la misma en condiciones de igualdad», disponiendo que la Generalitat «debe establecer un modelo educativo de interés público que garantice estos derechos». Por su parte, el art. 21.2 EAC garantiza a los padres el derecho a que sus hijos «reciban la formación religiosa y moral que esté de acuerdo con sus convicciones en las escuelas de titularidad pública, en las que la enseñanza es laica».

El FJ.20 de la STC 31/2010 ha señalado que el tenor de estos apartados «es manifiestamente inocuo en su contraste con los diferentes apartados del art. $27 \mathrm{CE}$, pues aseguran en idénticos términos el derecho a la educación».

Por otra parte, el Tribunal Constitucional ha señalado que el hecho de que se conceptúe a la enseñanza pública como laica sólo significa, «como se deduce de su tenor literal, que la enseñanza pública no es institucionalmente una enseñanza confiada a las confesiones religiosas, sin perjuicio del derecho de las madres y los padres a «que sus hijos e hijas reciban la formación religiosa y moral que esté de acuerdo con sus convicciones en las escuelas de titularidad pública», como el propio precepto reconoce en términos plenamente respetuosos con el art. 27.3 CE y con el art. $16 \mathrm{CE}$ ».

Creemos que el Tribunal Constitucional ha perdido una oportunidad para aclarar, de un modo más contundente y efectivo, de qué hablamos cuando hablamos de «enseñanza laica». Se ha dejado pasar un momento propicio para entender que dentro de los derechos consustanciales a la imprescindible defensa de la dignidad humana y del libre desarrollo de la personalidad, como arjé de nuestro sistema democrático, cobra especial intensidad el reconocimiento y protección de la libertad religiosa, así como la necesaria, y en cierto modo instrumental a efectos de garantizar la anterior, separación entre religión y Estado. Por ello se puede decir que no existe Estado Constitucional, en el último sentido axiológico del término, allá donde no se produzca esta separación.

La laicidad se sustenta sobre dos pilares. En primer lugar sobre la neutralidad del Estado, que implica igualdad en el trato dado a los ciudadanos en relación al fenómeno religioso; estricto mantenimiento de la neutralidad con lo que ello supone de prohibición del sostenimiento económico de las Iglesias. En segundo lugar, la laicidad sólo puede existir en aquellos Estados cuyos ordenamientos jurídicos reconozcan y garanticen la libertad de conciencia y el libre ejercicio del culto sin más limitaciones que el respeto del orden público.

La laicidad implica, pues, el respeto pleno a la diversidad espiritual. En ese sentido se torna lógico que el hecho religioso se enseñe en las escuelas no como asignatura dogmática, sino como un hecho cultural indispensable para el conocimiento del devenir

27 Carrillo, op. cit., pág.3. 
de los pueblos. Por ello, las personas encargadas de impartir esta materia deben estar en posesión de una titulación académica reglada por la enseñanza pública para que, de un modo culturalmente aséptico, se haga llegar a los alumnos el hecho religioso de la manera más objetiva posible. Así mismo, la laicidad implicaría el reconocimiento del libre pensamiento y del humanismo racionalista como una verdadera opción espiritual. Dado que de nada de esto se ha tratado en la STC 31/2010 entendemos que se ha perdido una gran oportunidad $^{28}$.

\section{IV.3. Garantías de los derechos estatutarios}

El capítulo IV del Título I EAC regula el mecanismo que garantiza los derechos estatutarios en los arts. 37 y 38 :

La STC 31/2010 (FJ 26 $6^{\circ}$ se pronuncia sobre la constitucionalidad del apartado $1^{\circ}$, segundo párrafo del artículo 37 EAC que prevé que los derechos reconocidos en los arts. 32 y 33 EAC $^{29}$ vinculan «también a la Administración General del Estado en Cataluña», al entender el Tribunal Constitucional que el resto del artículo no se encontraba impugnado, por lo que sólo nos detendremos en el análisis del párrafo señalado.

Entiende que el art. 37.1 EAC en cuanto extiende a la Administración del Estado en Cataluña la vinculación a los derechos reconocidos en los arts. 32 y 33 EAC ha de ser rechazado dado que la cooficialidad de la lengua catalana en la Comunidad Autónoma de Cataluña es una circunstancia jurídica sólo posible en virtud de una decisión reservada al Estatuto de Cataluña y que de ella se sigue, por imperativo constitucional y sin necesidad

28 CARrillo en op. cit., pág.3 señala, en la misma línea, que «seguramente, el único tema de los dos apartados de este precepto que podía suscitar controversia era el referido al carácter laico que el Estatuto prescribe que tiene que tener la enseñanza a la escuela pública (art. 21.1). El Tribunal resuelve de forma breve los reproches de inconstitucionalidad presentados por el recurso, argumentando que dicha referencia «sólo significa, como se deduce de su tenor literal, que la enseñanza pública no es institucionalmente una enseñanza confiada a las confesiones religiosas, sin perjuicio del derecho de las madres y los padres a que sus hijos e hijas reciban formación religiosa y moral que esté de acuerdo con sus convicciones en las escuelas de titularidad pública». Además, añade que «la expresa referencia al art. 37.4 EAC incluida en el art. 21.2 EAC disipa definitivamente cualquier riesgo de interpretación sesgada (...) de forma que reduzca o limite los derechos fundamentales reconocidos por la Constitución» (FJ 20). Pero la cuestión de la enseñanza laica no era ni es de orden menor. En este sentido, el Tribunal ha perdido una buena oportunidad — en éste y en mucho casos más de esta sentencia- para llevar a cabo una interpretación más ambiciosa sobre el alcance de los preceptos constitucionales, a raíz de la modificación del bloque de la constitucionalidad operada por la reforma estatutaria catalana. Porque hay que subrayar que la Constitución no hace ninguna referencia a la palabra laica o al laicismo en su texto, ya sea al referirse a los principios que informan la organización política del Estado (título preliminar), o cuando reconoce la libertad religiosa (art.16.1 CE) o el derecho a la enseñanza (art. $27 \mathrm{CE}$ ). Pero sí que se establece que ninguna confesión tendrá carácter estatal (art. 16.3 CE). Probablemente no habría sobrado que el Tribunal se pronunciara, por ejemplo, sobre si la enseñanza laica no sólo significa — cómo únicamente diceque la enseñanza pública no está confiada a las confesiones religiosas, sino si también es o comporta una forma de enseñanza que excluya en todo tipo de materias el hecho religioso o su enfoque se vea impregnado por convicciones religiosas. Especialmente, en un contexto educativo como el español, en qué una buena parte del presupuesto público en materia de enseñanza está dirigido a la escuela concertada (de titularidad privada, muy a menudo religiosa, pero financiada con dinero público). Por este motivo, el artículo 22.2 del Estatuto era un buen reto, que el Tribunal ha evitado».

29 Los artículos 32 y 33 se refieren a los derechos y deberes de conocimiento y uso de las lenguas así como a los derechos lingüísticos ante las administraciones públicas y las instituciones estatales. 
de intermediación normativa alguna, su condición de lengua oficial para todos los poderes públicos radicados en Cataluña, sean estatales, autonómicos o locales, asistiendo a los ciudadanos el derecho de usar ambas lenguas en sus relaciones con tales instituciones públicas» (SSTC 134/1997, de 17 de julio, FJ 2; y 253/2005, de 11 de octubre, FJ 10). En este sentido, el Estatuto «se limita a la descripción de las consecuencias genéricas propias de la cooficialidad del castellano y del catalán en el ámbito de la Comunidad Autónoma de Cataluña, cifradas en el derecho de opción lingüística de los particulares en sus relaciones con el poder público, sin privilegio o preterición de ninguna de ambas lenguas».

En relación al art. 38 EAC se le formulan dos reparos: que el Consejo de Garantías Estatutarias interfiere en el sistema de garantías de los derechos fundamentales y que establece la existencia de un recurso ante el Tribunal Superior de Justicia de Cataluña por vulneración de los derechos estatutarios.

El art. 38.1 EAC, tal como recuerda la STC 31/2010 (FJ.27º), atribuye al Consejo de Garantías Estatutarias la tutela tanto de los derechos estatutarios como de los derechos legales incluidos en la Carta mencionada en el art. 37 EAC, «de acuerdo con lo establecido por el artículo 76.2 b) y c)». El art. 76 EAC relaciona las funciones de dicho Consejo, entre las que se cuenta el dictamen sobre la adecuación al Estatuto y a la Constitución de los proyectos y proposiciones de ley sometidos a debate y aprobación del Parlamento y de los decretos leyes sometidos a convalidación del Parlamento, así como sobre los proyectos de decreto legislativo aprobados por el Gobierno. El Tribunal Constitucional entiende que no existe motivo de inconstitucionalidad puesto que el precepto se limita a confiar al Consejo de Garantías Estatutarias la defensa de unos derechos que no se confunden con los derechos fundamentales ni pueden redundar en su perjuicio o menoscabo, sin que del contenido del propio art. 38.1 EAC se derive cuál haya de ser la naturaleza de la tutela dispensada por aquel Consejo o el alcance en Derecho de sus pronunciamientos ${ }^{30}$.

$\mathrm{El}$ art. 38.2 EAC dispone que «los actos que vulneren los derechos reconocidos por los Capítulos I, II y III del presente Título y por la Carta de los Derechos y Deberes de los ciudadanos de Cataluña serán objeto de recurso ante el Tribunal de Justicia de Cataluña, de acuerdo con los procedimientos establecidos en las leyes».

Dado que, como resulta obvio, el legislador catalán no dispone por sí mismo de competencias para ordenar un sistema de garantías jurisdiccionales de los derechos estatutarios, el Tribunal Constitucional (FJ $27^{\circ}$ ) hace constar que pese a que la literalidad del artículo 38.2 pudiera parecer incompatible con la atribución al Estado por el art. 149.1.6 CE de la competencia exclusiva en materia de legislación procesal no es éste el caso debido a la remisión al principio de legalidad en relación a los procedimientos a seguir, ley que, obviamente, ha de ser ley estatal Sobre este particular ${ }^{31}$, el Tribunal interpreta que dado que el art. 38.2 EAC no se refiere específicamente a un concreto recurso

30 Debemos recordar, en este momento que el artículo 76.4 ha sido declarado inconstitucional (Los dictámenes del Consejo de Garantías Estatutarias tienen carácter vinculante con relación a los proyectos de ley y las proposiciones de ley del Parlamento que desarrollen o afecten a derechos reconocidos por el presente Estatuto) atendiendo debido al carácter vinculante de estos dictámenes por inmiscuirse indebidamente en competencias propias del Parlamento y del Poder Judicial (FJ.32 $)$

31 Ver Carrillo, op. cit., pág.3. 
del que conozca un concreto tribunal, sino que califica en determinados actos como «objeto del recurso» ante el Tribunal Superior de Justicia, ha de entenderse que no implica la introducción de «innovaciones procesales» ni supone una alteración «de las reglas procesales comúnmente aplicables».

\section{IV.4 DOS PRINCIPIOS RECTORES: LA PERSPECTIVA DE GÉNERO Y LOS MEDIOS DE COMUNICACIÓN SOCIAL}

El art. 41 EAC consta de diversos apartados en los que, bajo la denominación «Perspectiva de género», se recogen distintos mandatos dirigidos a los poderes públicos de la Comunidad Autónoma tendentes a conseguir la igualdad real y efectiva entre mujeres y hombres en los diferentes ámbitos social, económico y cultural, entre otros, así como a garantizar que las políticas públicas hagan frente de modo integral a la violencia sexista. En su apartado 5, único que ha sido impugnado, se dispone que «los poderes públicos, en el ámbito de sus competencias y en los supuestos previstos en la ley, deben velar para que la libre decisión de la mujer sea determinante en todos los casos que puedan afectar a su dignidad, integridad y bienestar físico y mental, en particular en lo que concierne al propio cuerpo y a su salud reproductiva y sexual».

Por su parte, el art. 52 EAC, denominado «Medios de comunicación social», establece en su primer apartado que «corresponde a los poderes públicos promover las condiciones para garantizar el derecho a la información y a recibir de los medios de comunicación una información veraz y unos contenidos que respeten la dignidad de las personas y el pluralismo político, social, cultural y religioso. En el caso de los medios de comunicación de titularidad pública la información también debe ser neutral». El apartado segundo, por su lado, señala que «los poderes públicos deben promover las condiciones para garantizar el acceso sin discriminaciones a los servicios audiovisuales en el ámbito de Cataluña».

Ambos preceptos han sido impugnados por exceder la reserva estatutaria sobre dichas materias, infringiendo la reserva de ley orgánica del art. 81.1 CE. Para el Tribunal Constitucional (FJ.28 y $29^{\circ}$ ) estos preceptos contienen mandatos dirigidos a los poderes públicos de la Comunidad Autónoma, únicos, por tanto, que resultan vinculados por los principios rectores en aquellos recogidos. Tal vinculación, por otra parte, se produce, por lo tanto, en el ámbito de las competencias asumidas por la Comunidad Autónoma e igualmente en los supuestos previstos en las leyes, lo que determina que la actividad de los poderes públicos en la prosecución de los mandatos establecidos habrá de atenerse, en cada caso, a lo dispuesto por el legislador competente, lo que incluye también, en su caso, las leyes del Estado.

En relación al artículo 41.5 EAC señala además el Tribunal Constitucional (FJ $28^{\circ}$ ) que «no puede observarse ninguna contradicción con el art. $15 \mathrm{CE}$, ni puede inferirse del enunciado en sí del art. 41.5 EAC dada su generalidad y abstracción, una indeterminación de la protección, en los términos constitucionalmente debidos, de la vida concebida, como sostienen los recurrentes. Ello sin perjuicio, como es obvio, de la posibilidad de impugnar, en su caso, la eventual adopción de políticas públicas que se pudieran entender contrarias al referido derecho fundamental. Pero de la redacción del pre- 
cepto en cuestión ni se derivan necesariamente estas políticas, ni, más genéricamente, proclamación alguna contraria al art. $15 \mathrm{CE}$ como revela el contraste de los enunciados de uno y otro artículo».

Respecto al art. 52 EAC, entiende el Tribunal Constitucional (FJ 29) que «en el mandato dirigido a los poderes públicos autonómicos de promover las condiciones para garantizar el derecho a la información y a recibir información veraz, así como la neutralidad de los medios de comunicación de titularidad pública y, en fin, el acceso sin discriminaciones a los servicios audiovisuales en el ámbito de la Comunidad Autónoma no puede apreciarse que por sí mismo, a falta de una concreta fundamentación que sustente el reproche que se dirige al precepto, resulte vulnerador de alguno de los derechos fundamentales y libertades públicas recogidos en los arts. 18 y 20 CE.»

\section{REFLEXIÓN FINAL}

Como hemos señalado, la STC 31/2010 no es la primera en la que el Tribunal Constitucional se pronuncia sobre la legitimidad constitucional de una declaración de derechos y principios rectores incluida en los Estatutos de Autonomía. La STC 247/2007, que resolvió el recurso planteado contra la reforma del Estatuto de Autonomía de Valencia, estableció que el contenido del Estatuto puede ir más allá del establecido, como de necesario cumplimiento, por el artículo 147.2 CE, por lo que no existe impedimento alguno para que el Estatuto, como norma institucional básica de la Comunidad Autónoma, incluya derechos en su texto. Sin embargo, el Tribunal precisó que los derechos estatutarios no son en realidad derechos subjetivos sino simples mandatos a los poderes públicos autonómicos. Ahora, con motivo de la STC 31/2010, se reitera en esta doctrina y se mantiene que los derechos estatutarios no son derechos subjetivos sino mandatos a los poderes públicos, abandonando la distinción establecida en la STC 247/2007 entre los que quedan vinculados a los funcionamientos de las instituciones y los que lo están al ejercicio específico de competencias.

El Tribunal entiende que estos derechos estatutarios no son derechos subjetivos sino mandatos al legislador, para diferenciarlos de los derechos fundamentales reconocidos por la Constitución, y, por lo tanto, los derechos estatutarios sólo vinculan al legislador autonómico. Esto supone, según el Tribunal Constitucional, que sólo serán exigibles ante los órganos judiciales cuando el legislador autonómico los haya desarrollado mediante ley. Igualmente, los derechos estatutarios son derechos materialmente vinculados al ámbito competencial propio de la comunidad autónoma; es decir, son las competencias reconocidas en el Estatuto las que delimitan el ámbito en que los derechos estatutarios pueden operar.

El desarrollo de los derechos ha de hacerse por ley, no siendo posible hacerse por el legislador orgánico estatuyente, dado que en realidad, no es que pueda hacerse más por ley autonómica; es que se hace cosa distinta, como corresponde en el juego de normas ordenadas con arreglo al criterio de competencia, y esto por razones que tienen que ver con la condición del Estatuto como norma institucional básica, por un lado, y con su vigencia territorial limitada, por otro. 
Esta interpretación sobre la legitimidad constitucional de la previsión estatutaria resulta, pues, de un alcance limitado y, tal como ha señalado la doctrina, ofrece puntos de crítica. En primer lugar, los derechos estatutarios no son siempre diferentes de los derechos fundamentales reconocidos en la Constitución. Y en segundo lugar, no están claras las razones por las que el legislador orgánico estatutario no pueda declarar, con una cierta extensión, el contenido esencial de aquellos derechos que incluya en el texto del Estatuto, por supuesto siempre dentro de su ámbito competencial propio.

En todo caso, y a pesar de las reticencias jurídicas expresadas, fundamentalmente relacionadas con la naturaleza limitada de su alcance, la «validación» constitucional de la inclusión de un catálogo de derechos en los Estatutos de Autonomía no deja de ser una importante y controvertida (recuérdense los votos particulares aludidos en este trabajo) aportación de la STC 31/2010.

TITLE: The effective constitutionality of the regulation of statutory rights in the STC 31/2010.

ABSTRACT: The possibility that the Statutes of Autonomy regulate rights has been a matter that constitutionalist has turned out to be specially polemic in the last years. The STC 31/2010 concludes this topic proclaiming the effective constitutionality of the regulation of statutory rights and establishing his limited scope. The Constitutional Court has added that the statutory rights are not actually civil rights but simple mandates to the autonomous public power. This supposes that only they will be exigibles when the autonomous legislator has developed them. The statutory rights are materially linked to the own area of the autonomous community.

RESUMEN: La posibilidad de que los Estatutos de Autonomía regulen derechos ha sido un asunto que ha resultado especialmente polémico para la doctrina constitucionalista en los últimos años. La STC 31/2010 concluye, de momento, este tema proclamando la efectiva constitucionalidad de la regulación de derechos estatutarios y estableciendo su limitado alcance. El Tribunal Constitucional ha precisado que los derechos estatutarios no son en realidad derechos subjetivos sino simples mandatos a los poderes públicos autonómicos. Esto supone que sólo serán exigibles ante los órganos judiciales cuando el legislador autonómico los haya desarrollado. Igualmente, los derechos estatutarios son derechos materialmente vinculados al ámbito competencial propio de la comunidad autónoma.

KeY WORDS: Rights. Statutes of autonomy. Governing principles.

Palabras Clave: Derechos. Estatutos de autonomía. Principios rectores.

FECHA DE RECEPCIÓN: 29.11. 2010. FECHA DE ACEPTACIÓN: 26.01.2011 